\title{
Rod eutectic growth in bulk undercooled melts
}

Junfeng $\mathrm{Xu}^{1}$, Tao Zhang $^{2}$, and Peter Galenko ${ }^{3}$

${ }^{1}$ Xian Technological University

${ }^{2}$ Institute for Frontier Materials

${ }^{3}$ Friedrich-Schiller-Universitat Jena

May 17, 2021

\begin{abstract}
This article proposes an analytical model to understand the rod-growth of eutectic in the bulk undercooled melt. Based on the previous derivations of the lamellar eutectic growth models, relaxing the assumptions of small Peclet numbers, the model is derived by considering melt kinetic and thermal undercoolings. The intent of this model is to predict the transitions in eutectic pattern for conditions of the low and high growth velocity. In addition to investigation of the transition between lamellar and rod eutectic pattern, mathematical simplifications of solving Bessel function are presented as well, which is the most important priority to model calculation.
\end{abstract}

\section{Hosted file}

MMAS_rod_2021_04-29 -corrected.pdf available at https://authorea.com/users/343920/articles/ 522351-rod-eutectic-growth-in-bulk-undercooled-melts

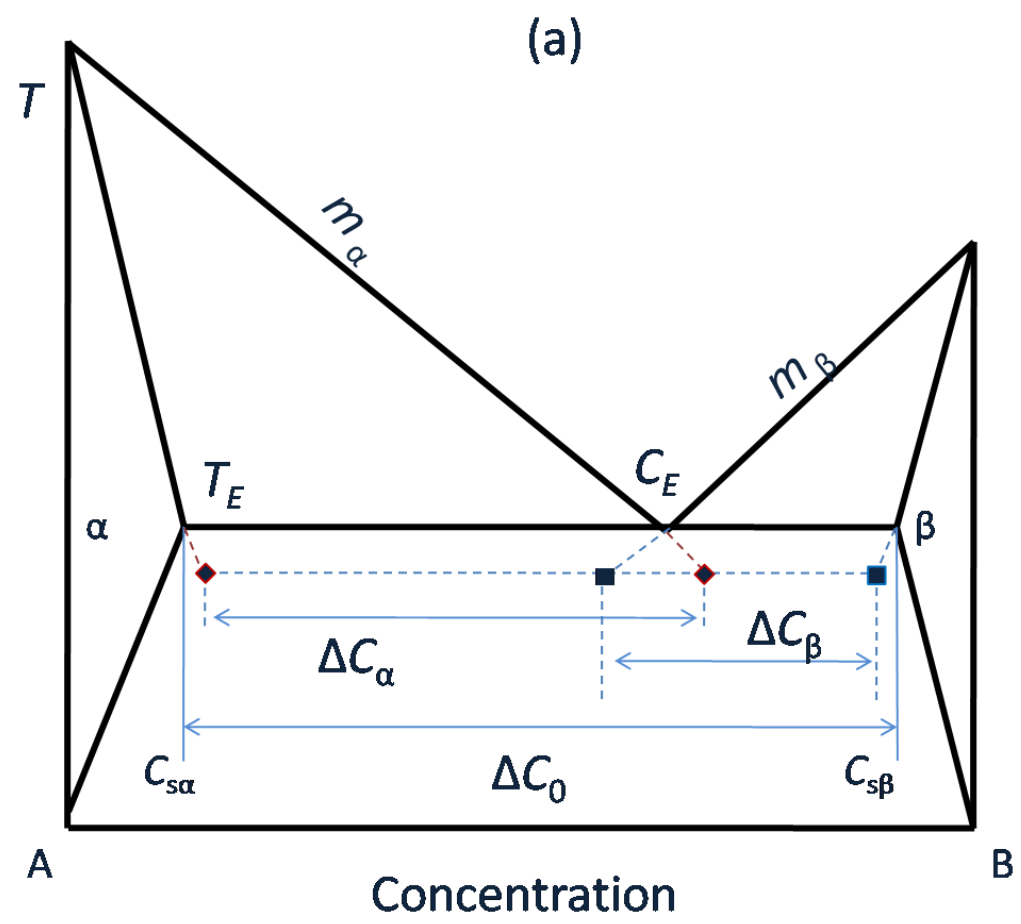


(b)

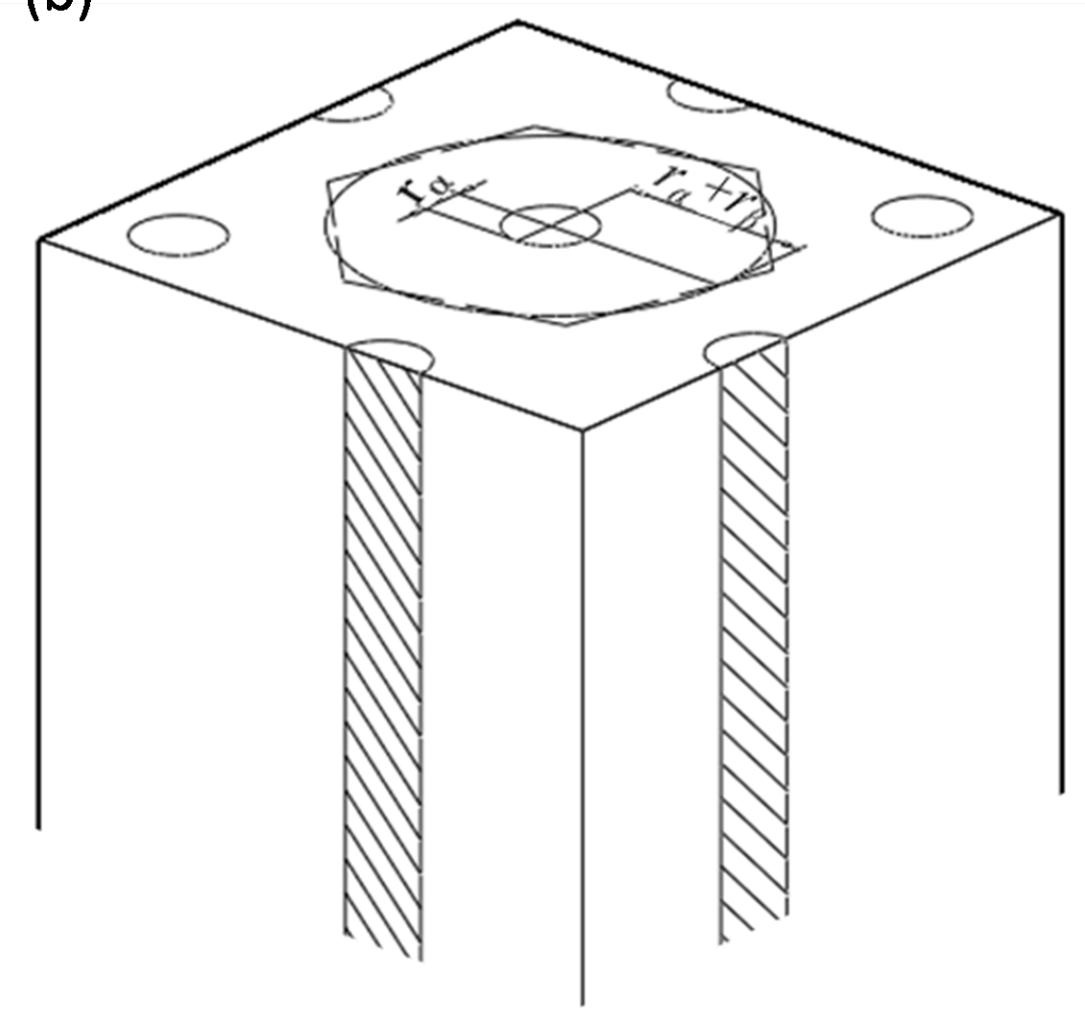

(a)

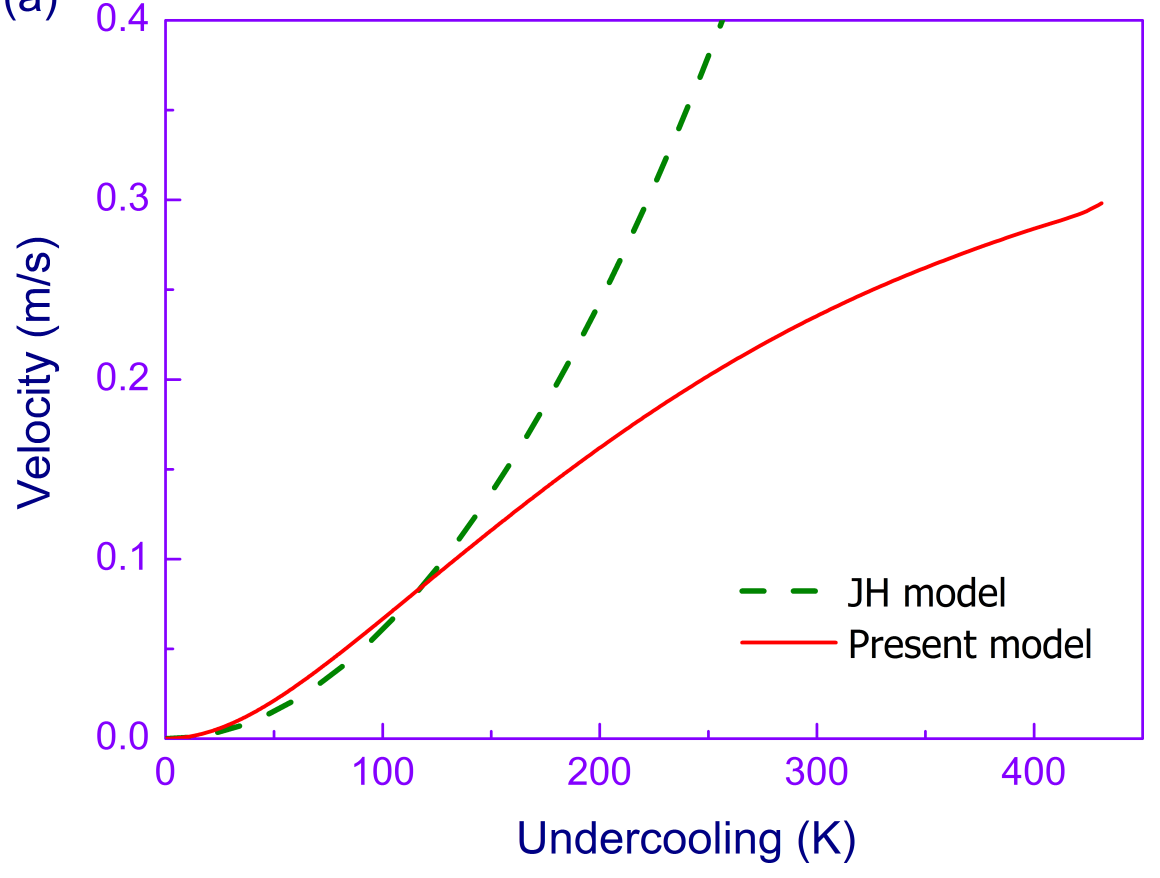



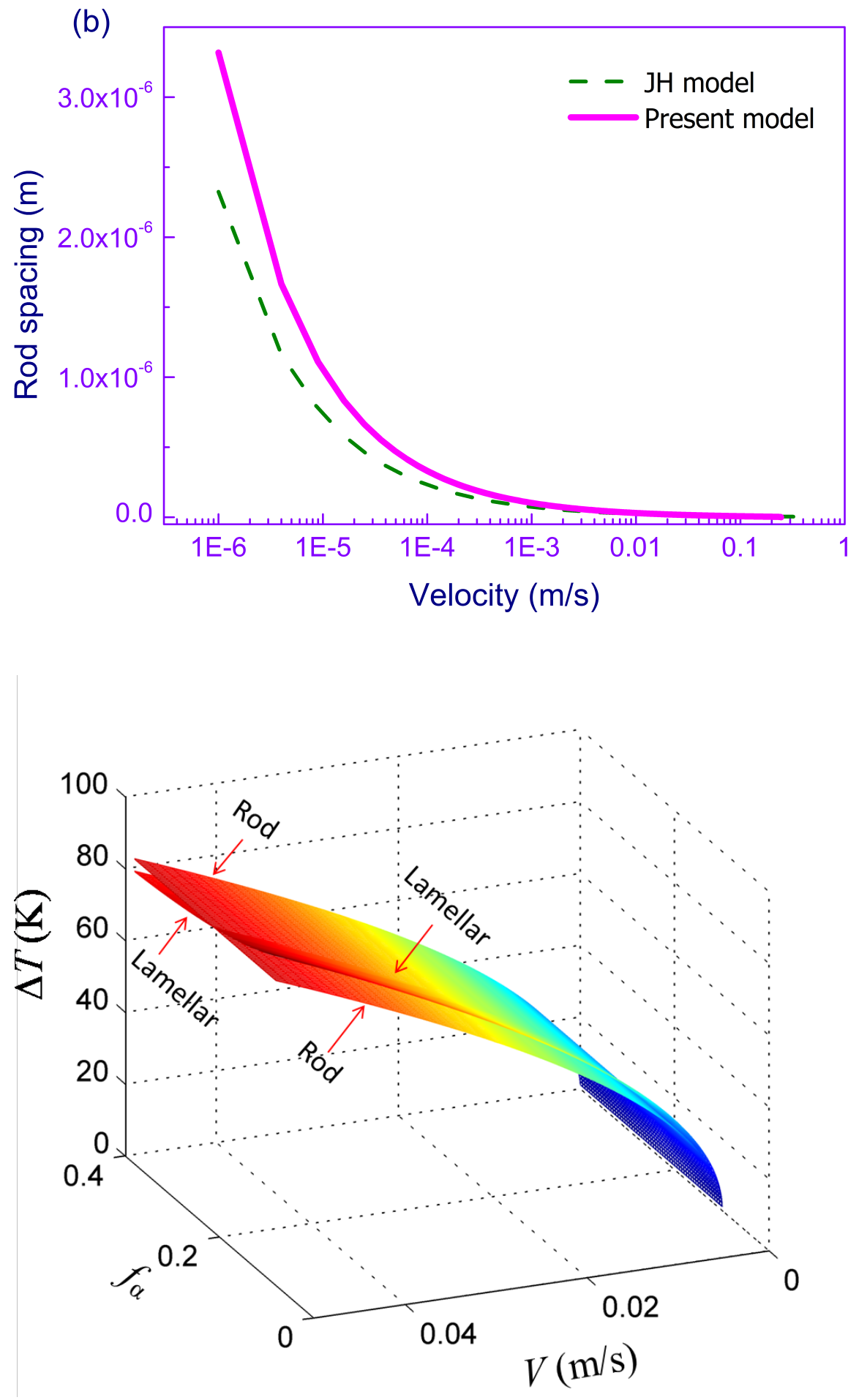

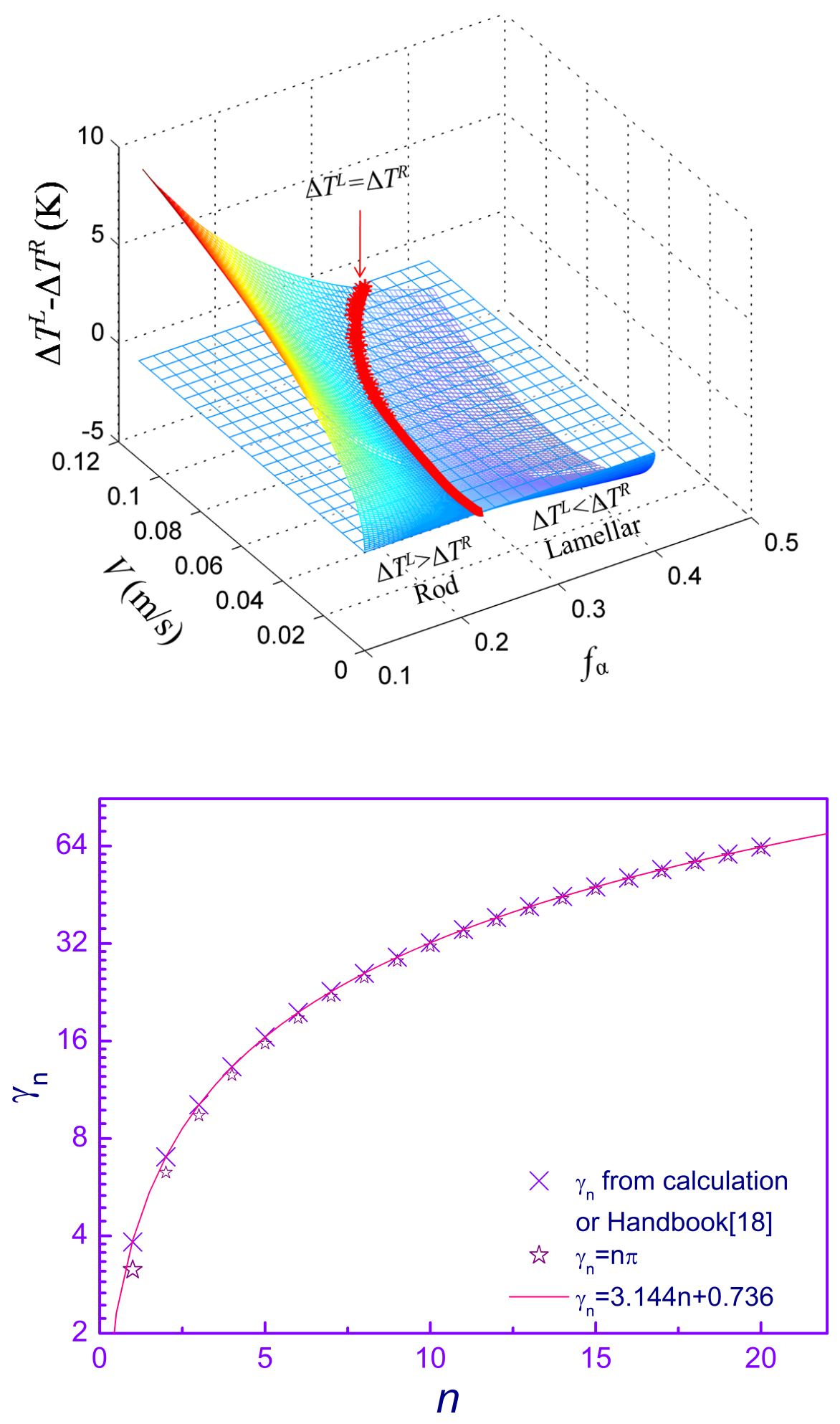


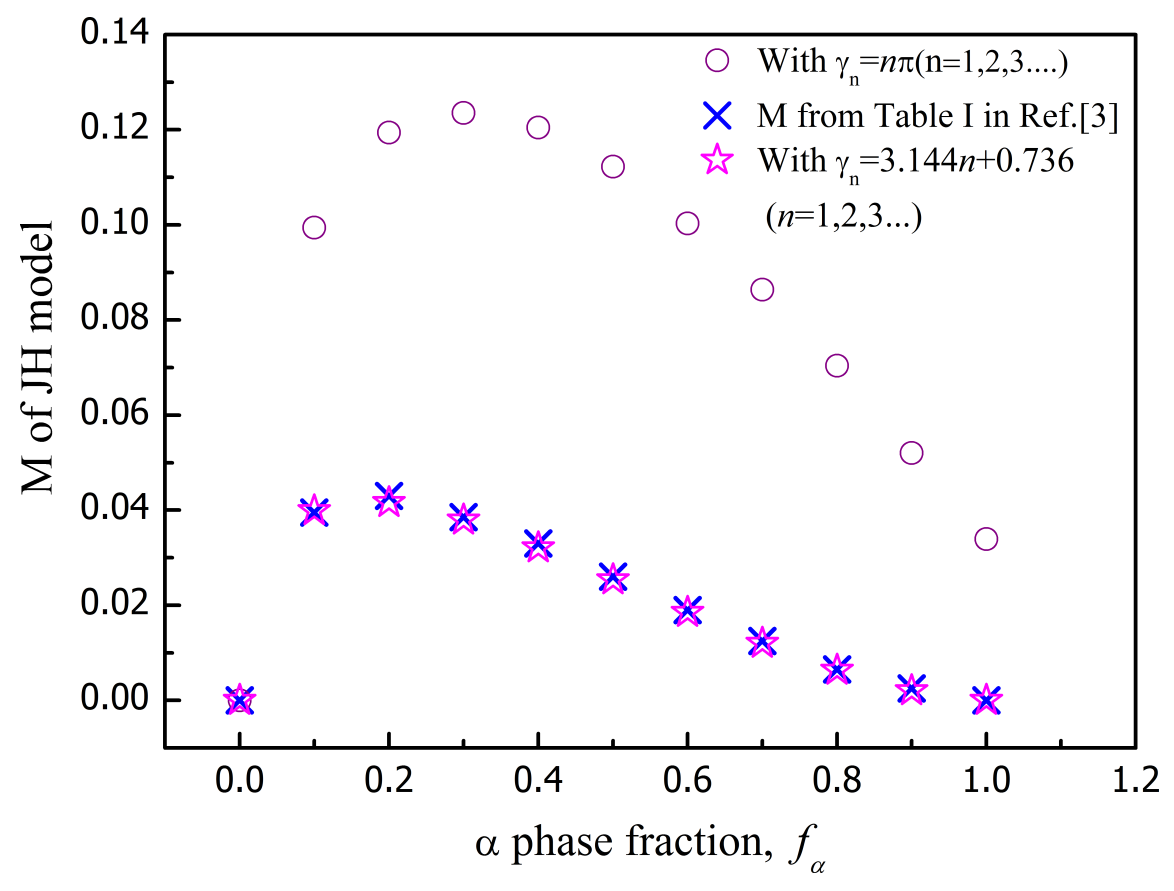

